\title{
11 \\ The incorporation of user needs in telecom product design
}

\author{
Vivien Walsh, Carole Cohen and Albert Richards
}

This chapter reports some observations of a user-oriented design project in a firm supplying telecommunications equipment. It is part of a larger project in which we also observed the design of a telecom service by a network of telecommunications service supply firms, and several projects in a consumer organisation which evaluates telecom and other electronic products and services. Our approach was to observe these projects as they were unfolding. The rationale for studying ongoing design work was to observe the process by which design decisions were made, while various options were being considered, and before each decision had become, in the minds of those concerned, justified as the 'best' and possibly only option to choose. A design often becomes the preferred option as it is adopted, commitments are made to it, rationalisation takes place, support is enlisted and interests become bound up with the choice that has been made.

One of our objectives was to use our observations to contribute to the understanding of the management of the design process. The organisation sponsoring the research was the Design Council, whose own objective is the promotion of effective design in manufacturing and service industry. The other objective was to contribute to the body of academic work currently being undertaken, in Manchester and elsewhere, which seeks to analyse design and innovation activities within an interdisciplinary framework of the social sciences, exploring the potential for rapprochement among technology management, sociology of innovation, economics of technological change, anthropology and other disciplines.

\section{Demand, markets and user needs}

Markets and market signals are extremely important phenomena in neoclassical economics, governing the allocation of resources and decisions about technological change. The approach of neo-Schumpeterian economics, in contrast, focuses on entrepreneurship, firm capabilities and other supply-side factors. It stresses the role of the firm, not as an actor which makes decisions 
on the basis of profit maximisation, given the prices of inputs and outputs, but one which operates in an uncertain environment which does not allow all the likely outcomes of decisions that may be taken, which must generate knowledge (at a cost), which will take risks, which goes through a learning process, and which develops strategies not based solely on 'objective' knowledge, but also influenced by its own culture, ethos and guiding philosophy.

On the whole, we are in agreement with this latter approach, but believe that it tends to neglect the demand side, and in particular the environment in which products succeed (or fail), named the selection environment in the neo-Schumpeterian tradition but less widely studied than supply-side factors (Nelson and Winter, 1982). In refocusing on the demand side, we are not in any way embracing a neoclassical perspective. The selection environment includes markets, but is also strongly influenced by non-market factors such as government regulation, standards and professional recommendation, all of which may determine whether or not a market will exist, some of which are particularly important in telecoms. These expansions of the concepts of the supply and demand sides may thus in some senses be said to incorporate into economics ideas which are not strictly economics, concerning behaviour and culture (the province of sociology and anthropology) and motivation (the province of psychology). While our methodology has essentially been sociological, our conceptual framework draws on evolutionary economics as well as sociology.

Clearly, if a firm intends to market a new product, process or service, it makes sense to produce one that meets customer needs in some way, or it will not be very successful. This would seem to be a fundamental principle of business, and firms spend substantial sums on market research trying to find out what people do want, and on market trials which seek to discover customers' responses to products they have already developed. In spite of this, it is perhaps surprising how often firms (and designers) express the view that they 'just know' what customers want; or make assumptions based on their own wishes, thinking that customers will want the same kinds of products as they do themselves (Akrich, 1995; Cohen and Walsh, 1995). There are many anecdotes that indicate that such assumptions can be astonishingly successful - or disastrously mistaken. But company policy cannot be built on gambles of this kind.

Sometimes, however, it is not possible to tell from market research whether there is a potential market for a new product. If an innovation is radical, the firm will not be sure exactly who is likely to want to buy it; while potential users will not be aware that they have needs that the innovation might meet (Miles, 1993). In such cases, markets may have to be created. Advertising plays a role in market creation, but is not likely to be very successful where the innovation represents a substantial departure from known products.

Von Hippel (1988) has written about cases where users have made equipment for themselves, and in due course have got it manufactured in quantity for the market, either by involving a manufacturer or by going into business 
themselves. Lundvall (1988) has written about the role of user-supplier interaction in the success of innovation. Collaboration in the development stage may take place between the producer of an innovation and lead users - who are equally innovative in adopting the new product, service or process. The provision of technical services by the suppliers of an innovation may assist customers to understand the properties of the new product and thereby make better use of it (e.g. new materials). And the provision of training for customers may be necessary so that they can use the new product (e.g. early computers). These interactions with users all contribute to the creation of markets, and to the creation of customer loyalty and 'lock-in' in anticipation of the appearance of competing products.

Lead users may modify a product so that it meets their needs better, at the same time as they alter their own tasks so as to make best use of it, and by their example enlist other users to try it out. In this sense there has been a simultaneous construction of technology and the market, and boundaries have become blurred between late design and early adoption (Mangematin, 1993; Mangematin and Callon, 1995). User-supplier interaction and 'late design' by lead users do not always involve the firm in learning more about its users in advance of product launch, or deliberately taking users into account in product design, but can provide a path for doing so in the future.

In the computer industry, concern with user needs began to focus on issues of human-computer interaction (HCI) with the growth of the PC market among households and business users who were not computer experts. Dedicated research centres on human factors started to appear in both public and private-sector organisations, such as Human Factors \& Advanced Technology (HUSAT) at Loughborough University (UK) and human factors laboratories in the large firms of Xerox PARC, Apple, Microsoft and IBM in the United States. The dominant paradigm for taking user needs into account in this industry has been the 'usability' study, in which a new item of hardware or software will be tested to make sure that the intended users can see how to operate it successfully, achieving what they expect to achieve without recourse to frequent use of manuals or special courses.

There have been several changes of emphasis in the objectives, techniques and methods used in usability studies (Hull, 1992, 1997; Richards et al., 1996), shifting progressively away from formal evaluation methods carried out in the laboratory by expert ergonomists and psychologists, whose focus is the appropriate shape, weight, labelling of keys, angle of display and so on to match the physical and psychological characteristics of the intended user. The 'empirical' approach to usability testing moved away from experts and ergonomics, towards observations of users or representatives of users interacting with equipment, though still in a laboratory-type situation. Most recently there has been a focus on observing 'real' people using the product or a prototype, with increasing emphasis on the context in which it is used, their own home or workplace, and qualitative as well as quantitative evaluation. Thus, for example, ethnographic studies, stemming from sociology (especially 
ethnomethodology) and anthropology, have been carried out in which observations are recorded on audio or video tapes of 'real people' doing 'real work' with computers and other IT-based systems in their normal workplace environment. The recordings are then analysed later using conversation analysis (de Fornel, 1993; Harper and Hughes, 1993), interaction analysis (Suchman, 1993) or distributed cognition techniques (Hutchins, 1995).

The telecommunications industry has adopted the concern about HCI, human factors and usability which first emerged in computer hardware and software firms. This is partly due to the influence of the computer industry, as a result of the increased integration of computer technology and telephony. It is also partly due to the increasingly competitive environment in which telecoms firms are operating as a result of deregulation and privatisation, which have enabled the entry of increasing numbers of overseas competitors in most former national monopolies' home markets, on the one hand, and a shrinking market on the other hand, resulting from cuts in network operators' expenditure on equipment. Increased competition has encouraged telecom equipment firms to place more emphasis on meeting the needs of users, or at least making products they can use easily. In turn, the rhetoric of concern with user needs may be used as a marketing device.

\section{Nimrod PLC}

The case reported in this chapter took place at a telecom equipment supplier, and involved the observation of a usability trial about to start in their Business Systems division. We have called this firm Nimrod PLC (and Nimrod BS), to preserve its commercial confidentiality. This was the first such trial Nimrod had actually carried out, although it had adopted a user-oriented strategy some two years earlier. Working out the practicalities of implementing the strategy, usability training, developing guidelines and generally winning the support of staff throughout the firm for a usability orientation had all taken place, but so far no 'real' usability trial had been carried out as part of the development of a new product. We started our observations in July 1995 , and continued to make them until the end of 1996, though our visits were more and less frequent at different stages of the development project. We interviewed several times all the staff involved in the usability and the product design processes, observed the usability trials, attended all the formal project meetings, and attended those of the informal meetings we could manage (as it was only possible to attend ad hoc meetings if we were already on site). All the first names mentioned in the chapter are those of members of the design team, changed to maintain their anonymity.

Nimrod used ergonomic consultants or in-house staff to advise on the match between human users and the physical properties of their products. They then carried out in-house usability trials, in which they used members of their own staff to test the usability of their proposed products. In the first place the surrogate users were colleagues of the design team, engineers working on other 
projects. Then they asked staff from non-technical departments, such as accounting, marketing and secretarial services. The trials took place on company premises, but attempts were made to make the environment as unlike a laboratory as possible.

The project we observed at Nimrod was the design and usability testing of the P96 range of telephones intended to be used with the firm's private switching systems and networks. The firm's goal was to develop 'new, more powerful, flexible and user-friendly products that support international industry standards in advanced telephony features and applications, and advanced computer telephony integration'. The P96 range was to offer basic features on the simplest model; and advanced functionality, such as programmable feature keys and key system keys, on the top of the range model, with a display that would facilitate its use, enable the users to navigate the programming, and provide call information when the phone was in use.

Most of the functionality was supplied by the network, but it was the phone on the desk that the business user would use to access these functions, and therefore judge for its user-friendliness, and for the extent to which it made intuitively obvious which features were available and how to use them. Indeed, the terminal (telephone) was to be designed explicitly to encourage the use of the features available on the ISDX (the switch), without reference to user guides or training. Nimrod was concerned, as were other firms in the information and communication technology (ICT) industry, that users should be able to focus on the task they wished to accomplish, without needing to understand the technology that made them possible, or indeed be aware of it. This is known in the industry as 'transparency'.

Three groups of design issues ${ }^{1}$ discussed by the team were:

1 Issues concerning the physical design.

2 Issues concerning the design functionality.

3 Issues concerning the user guides.

The usability procedures we observed concerned the first two of these.

\section{Preparing for usability testing}

Peter, the 'design authority', ${ }^{2}$ started to prepare the usability plan at the design stage of the phase review process (see Table 2). ${ }^{3}$ The document would describe how the team was going to approach the problem of usability testing and go about doing it.

The core project team then provided the necessary resources to look into usability issues, running the usability tests in parallel with other design and development work on the terminals, so that all aspects of the terminal development were covered at the same time. Initially, Rob, an engineer taking on the title of Usability Co-ordinator, was going to co-ordinate the testing that was meant to start the last week of July 1995. Another engineer, Alan, was to be in charge of developing the simulation tool for rapid prototyping that 
Table 2 The phase review process

1 Concept generation

Development of concept brief by multidisciplinary team looking at technological feasibility, price, manufacturing feasibility, potential sales and short-term profit.

Phase Review I-Review of concept brief

2 Feasibility study

Production of a business plan

Phase Review II-Review of business plan

3 Definition of the triangle of time, cost and requirements

Appointment of Project Manager, definition of technical specifications and production of the following key deliverables:

- Marketing plan

- Marketing requirement specification (MRS)

- Product requirement specifications

- Project management plan

- Engineering plan

- Test plan

- Customer service plan

Phase Review III

4 Development

Design

Implementation

Phase Review IV

5 Testing

At least three months' technical and safety testing before it is on the market

6 Controlled release

7 Full release

8 Withdrawal

Note During each phase, plans are drawn up to show how the next phase will be implemented. The phase review at the end of each phase evaluates these plans and gives the authority to pass to the next phase. The phase review process acts as a control mechanism for new product development projects.

was to be used for testing the interface. Rob was to take the usability criteria defined in the usability plan and, looking into the simulation tool and the various hard model prototypes of the telephone, he would 'redesign' the usability plan accordingly for future evaluation. Rob was seen as the central usability resource that would look after all usability aspects of the terminal and be in charge of the future planning and co-ordination of all usability activities. Other people would come in later on, to look into usability issues related to specific design aspects of the terminal. According to Jack, the engineering team leader, usability issues were 'a massive input'. In Rob's words: 
The way I understand it at the moment, it is that my boss wants me to become involved in P96 in terms of usability. Now I don't known what they've actually planned to do. It's certainly the case that in the past when we've made terminals there's a number of things that we got entirely wrong.

The project core team members all recognised the need to carry out 'usability exercises' as a way 'to try and address the issues that [were] being raised as a result of the work ... done at the front end'. In other words, usability exercises were thought of as a problem-solving tool to find solutions to the design issues raised in the design and development work.

\section{Physical design}

There were two types of casework (casing) design, one for the two more advanced terminals and one for the two more basic ones. Usability testing was to address the aesthetic acceptability of the form or shape of the terminal, and whether the physical design lent itself to use. ('It might look pretty on the desk but can you actually use it?') In relation to the latter, the questions to be answered concerned the shape and size of the terminal; the position, spacing, layout, labelling and feel of the keys; the angle, size and contrast of the display; and the weight, shape, dimensions and feel of the handset.

Before we became involved in the project, Nimrod's design consultants had supplied several proposed casework and handset designs, two of which had been recommended by the consultant and agreed by Nimrod as optimally meeting their initial specifications. The firm's ergonomic consultants had also reviewed four previous Nimrod terminals and the two preferred designs for the new range, against European Telecommunications Standards Institute (ETSI) guidelines and their own accumulated expertise, and made a number of recommendations.

The usability studies sought the preference of users for one or other proposed design along a variety of measures, as a result of which some changes were decided upon (e.g. the weight of the handset). Other changes were made as a result of lock-in or compromise. For example the keys were labelled so as to be consistent with previous Nimrod models (expected by existing customers) or mobile phones (expected by some of the target customers). The angle of display was chosen as a compromise between the outcome of the usability trials, the ergonomic consultant's recommendations and the need to fit electronic components into the space allowed. The usability exercise was more to confirm that the choices made were acceptable than to obtain feedback that might change the design significantly.

\section{Functionality}

The functionality was tested almost entirely in-house by the Nimrod team. The logic of the menu structure was an important issue of the human- 
machine interface to be tested by the usability procedures. Also subjected to the usability tests was the sequence of key presses required for programming, for adjusting the volume of the headset, handset, speaker and ringer, and for setting the data port. These were tried out with the surrogate users. After several discussions in which different styles of managing the trials were put forward by different team members, the engineers decided to be as openended as possible in these trials, first letting the user 'play' with the machine like a child with a new toy, trying out various possible functions as purchasers of new pieces of equipment are wont to do.

In principle, they tried to make sure that the trialists did not feel that it was they who were being tested, rather than the equipment, but many of the surrogate users were nervous of breaking the equipment and self-critical if they could not work out what to do. Engineers from other teams were the most critical (of their colleagues) but the least likely to have problems. The non-technical triallists all experienced some problems, but the accountants were more likely to blame themselves. Some of them were clearly intimidated, expressed nervousness, and sometimes thought they had broken the telephone. Despite their good intentions the engineers were not entirely blameless in this, some of them expressing their own discomfort by overheartiness and jokes, and demonstrating some (possibly unconscious) preconceived attitudes by calling the user representatives 'testees' - a word which they made up, but implying that the person is being tested rather than the one doing the testing (which logically should be 'tester').

\section{The simulation tool for rapid prototyping}

In order to carry out usability trials on the functionality of the engineering design, the terminal under development was modelled using a rapid prototyping tool, developed as part of the project by Alan. This was a computer simulation of the functions of the terminal under development, using the requirement-capture tool set, that is, product requirements stored in the computer from previously handwritten requirements. It was operated with a mouse, or (later) could even be connected to a solid model of the telephone, so that the user could press buttons and so on, and the computer acted as a 'virtual telephone'. Different versions of the simulation could be brought up on different workstations and made to 'talk' to each other as if calls were being made between two telephones. The interaction between the two thus became observable: it was possible to see the results of the phone call being made by another party to the virtual terminal on the screen in front of you.

The objective, Colin (the project leader) pointed out, was '[to release] products that people can actually work with, and that of course, is the ultimate test, but we should be able to follow up a lot of major issues using this environment'. The immediate aim was twofold, namely:

1 The 'traceability' of design choices, downward from the requirements into the simulation model, on to the functional specification document and 
down into the design. The traceability of design decisions meant that learning could take place in the organisation. If a design choice is made that contributes to a later problem, identified during usability testing, the sequence of events and decisions can be traced back, and procedures revised for the future. Next time it may be easier to see which decisions should be left open, and where certain decisions were likely to have downstream consequences. It also, of course, makes the whole process more visible and the individuals making decisions potentially more accountable. Usability testing may thus become a way in which previous design choices are justified.

2 To force 'design issues up front' and allow 'marketing and other design authorities [to have] more of an involvement', thus reducing the risk of making 'bad' design decisions, and making sure that 'you know the thing is correct' before going into implementation and development (interview with Alan, 1996). This meant that decisions about design, and with respect to the user, could be taken even before any commitment was made to the specific structure and architecture of the system, before codes were 'cut' for the terminal software and firmware (thus placing constraints on the menu structure and logic) and before the tools necessary to make plastic moulds (for the manufacturer of the casing) were developed.

The idea was thus to be able to explore issues of usability before a working model had been developed, and therefore before certain irreversible decisions had been made. The output of usability evaluation was then to be analysed and assessed, and decisions were to be made on how to incorporate the feedback of the exercise into design specifications.

\section{Usability testing as a means of testing already made design decisions}

There was consensus in the team as to the role and purposes of a usability evaluation procedure, evident in the statements of various members of the team. Commitment to the necessity and usefulness of this new concern during the design process seemed to have been built from top down, as the following remark by Rob, the usability co-odinator, showed:

The idea of the functional model [the virtual model] that Jeff ${ }^{4}$ is promoting is that before we actually get into even making small mock-up prototypes ${ }^{5}$ we should be able to test the functionality and usability. We should be able to give some people some tasks to do and say, 'Programme the terminal to behave this way,' without telling them necessarily how to do it, and just sit and watch what happens. Through this let them get half-way through a task and then say, 'Well, you've got an incoming call,' or whatever, 'what's going to happen now? So that's the first level of trialling that I want see performed in a controlled way, a professional way.

It was established as part of the project brief that the use of the terminals should be intuitively obvious, so that users could find and use all their functions without special training or constant reference to manuals. It was also 
agreed among the project team that different kinds of users with varying levels of prior experience should be able to use the terminals equally easily for example, with step-by-step guidance for novice users and short cuts for experienced users.

From the start of the project, usability issues had been stressed as paramount, and design choices had been made with concerns about the userfriendliness of the terminal range. As the project manager Colin told us:

Usability has been at the back of our minds so that we have been careful not to take any decision that can preclude any usability requirements, but Jack and I have spent our days making absolutely certain what we are getting in terms of number of buttons, and features, and things like that.

And Jack, the engineering team leader:

Colin and I right from the start took into account all the terminals, Nimrod ones, non-Nimrod ones, our experience, and we were very reluctant to commit right up front to a set number of buttons and any specific set of features. We did not want to make a commitment without doing a certain amount of research, and even now that we have decided on the number of buttons on the terminals, we are making sure that the features associated with those buttons are completely flexible and movable. We have made our best guess, what we will now do is test that best guess. We are doing that in a number of ways. You have seen Alan with his simulation model; we are having a hard version, an actual solid model being made up to work as well. ${ }^{6}$ That is a hard version of the wooden one, that is, actually a hard version of what the final one will be, not perfect, but at each of the stages we will be making refinements and then doing testing. Obviously we have set the number of buttons now.

Although the whole team had been very conscious of the usability issues from the beginning, the actual planning of usability testing activities came somehow late in the course of the project, which had started some time before the team began thinking about how to carry out usability exercises. Table 2 shows the phase review process, the stages through which a development project had to pass. The usability trials were planned during the design phase, to take place in parallel with the other design and implementation activities. Logically, it would appear that usability should have been evaluated during the previous stage of project definition, the phase in which the marketing plan, marketing requirement specification, product management plan, engineering plan, and test plan were being developed. As it was these were all developed, and had been agreed upon, before the usability evaluation exercise.

Furthermore, as a result of the firm's user-oriented product development strategy, a generic document was available on how to do usability testing, but in practice the engineers did not know what exactly to do in the specific case they faced. This was the first time they had done a usability exercise and many of the details had to be decided on an ad hoc basis as the went along. As Rob said, 'I don't know what they've actually planned to do.' Jack's comments show that certain decisions about the design of the product had already been 
taken ('We have made our best guess' and 'We have set the number of buttons now') and that usability evaluation was to be a means of testing those decisions, with a view to making only a few changes where necessary and where it was still possible (for instance, 'The features associated with the buttons are completely flexible and movable'). It was not an open-ended exercise, where user reactions could modify any feature.

\section{Ad hoc decision making and taking situated actions}

The usability testing was an iterative process in which minor modifications would be made, the terminal retested and further modifications proposed. Despite the training and the generic guidelines, issues often came up which the engineers had not expected or thought about in advance, and they had to deal with them on an ad hoc basis, working out how to apply their training to the specific case of P96. For example, it became clear that different users have different 'mental models' of how the terminals will work, based on past experience, for example with other telephones. They could not assume that there was a 'correct' model: that one person's 'mental model' was better than another's. They had to find a model that people could relate to, whatever their background and experience, by measuring the design against 'essential' characteristics and criteria apparently external to the design, such as logic and consistency. The usability adviser demonstrated this to the rest of the engineers by setting them a programming task which some of them could not carry out, simply because they were expecting the procedure to be slightly different. This made the team aware of issues that might face 'real' users, and which they had not anticipated.

Jeff. Alan and I cooked up a couple of quick tasks, only very simple ones, but key ones internal to the actual functionality of the model that we were trying to demonstrate, and then got Colin and Pete over and sat them in front of it and said, 'Right, I want you to programme a number store on this phone,' and watched what they did.

Carole. So what happened?

Jeff. I tried to play a bit of the devil's advocate. ... I sat there and said, 'Right, what do I do next?' Because there was no immediate guidance.... I could have guessed which button to press, but I just played a bit dumb.... Well, he will tell you.... Carole was asking about the first semi-trials that we did, when I got you and Colin to try and use the Statement model....

Pete. Yes, you set a trap for us

Jeff. No, I didn't set a trap, Pete.

Pete. Well, he put me through hell!

Jeff. It depends on the background people come from, you see. When you say to somebody, 'Programme that key,' or 'Programme the speaker volume' I think that was the first one we started from - I thought that was relatively easy and we'd get through that quite quickly. Pete from his background instantly went to the speaker key, saying 'Programme speaker key,' and expecting something to happen. And, of course, it's not done that way, it's been done through a top-level menu. 
Pete. It didn't work, so I tried other things.... I went through three or four different models. I've got three or four models I carry in my head, on how I think appliances will work, based on my own previous experience of systems. So it's probably driven by my intuitive feel for this.

Jeff. At that particular point I was trying to prove that we weren't ready, that we needed to put some serious effort into getting this thing ... If it was going to be intuitive, then we had to put some serious effort in. There were a couple of key points I wanted to put across. One was, people didn't have the same model as to how to programme certain aspects.

Pete. They didn't all have the same mental model.... You can't prescribe the mental model people carry around in their heads, because it's the result of experience. You can't say what experiences people will have prior to coming across this particular instrument. So you have to make it logical and you have to make it relatively -

Jeff. Consistent.

Pete. Relatively foolproof, so that if people make assumptions, those assumptions don't carry them into areas which they're going to find difficult to recover from.

The experience of implementing a usability process meant incorporating a new set of design practices, with implications for project management, design schedules, the phase review process and design stages that would fit in with the existing organisational structures (the firm's specific combinations of project teams, functional departments and matrix management structure) and learning how to deal with the potentially disruptive effect of usability studies on the existing organisation of work. The team learned as much about how to carry out a usability test as they did about the users.

\section{From user needs to the representation of stakeholders}

Who are the users?

The Nimrod team did not carry out their usability trials in the way favoured by some of the firms mentioned above, that is, making observations of 'real' users in their own normal workplace settings. They used some expert tests carried out by their ergonomic consultants, and the usability tests they did themselves were carried out in-house using various people from within the firm to represent end users. Even if they had used members of the public, they would not have necessarily been representative of the range of end users likely to buy or use their product, but in any case they ruled out such a trial for various other reasons. One important reason concerned the commercial confidentiality issues that would be raised by showing their prototypes to outsiders. ${ }^{7}$ Another was that they had no direct contact with their own end users, because their immediate customers were distributors, who themselves sold Nimrod's products to end users.

We found that the 'Who is user?' issue was not a trivial one. As was the case with Nimrod (and the other firm we studied, not reported here, but named by us Hermes), the principal firm owning the intellectual property 
associated with an innovation may have used external consultants to design the casing in which to place its particular combination of electronic components and software; and another set of consultants to advise on ergonomic matters. The product may be subcontracted for manufacture (possibly to more than one firm) and sold to a distributor who will then sell it on (either as an 'own brand' or under the first firm's brand name and logo) either to domestic consumers or to other businesses. Where the customer is another business, the purchase decision is likely to be made by people who are more expert in the technology of the supplier firm than the range of staff likely to find themselves operating the new product.

In addition to that complex supply chain in which value is added and a series of market transactions take place, within the innovating firm it is increasingly likely that cost centres and other forms of 'market' mechanism will have been introduced, so that one department may have to sell its services and other output, literally as well as figuratively, to another. Departments are now linked by market-type relations as well as by hierarchical management structures. This was also the case in Nimrod (and Hermes).

At the same time, there has been an increasing tendency towards partnerships between organisations, including between potentially competing firms, in the production of innovations. These alliances are sometimes quite long-term ones, based on trust. As a result the organisational structures within which innovation takes place ('alliance capitalism', in the words of Dunning, 1997), is not the more or less hierarchical arrangement of a conventional firm. Neither is the relationship between the partners a conventional market one, since it involves commitment over a period of time, and value is created by the partners and not just exchanged. There is now a substantial literature on this issue (see, for example, Coombs et al., 1996, for a review), but for the purposes of our research there are two points to make. First, we have found that the job of the design team in a high-tech industry where firms collaborate is just as likely to be the design of the organisational arrangements for the development and delivery of new products and services as the design of the products and services themselves. As we have said elsewhere (Walsh, 1996), 'Design as an activity links many of the functions in the business enterprise and its environment and, conversely, building such links is an essential part of the design and innovation process.'

Second, as the above discussion has shown, the issue of who exactly is the 'user' is no longer straightforward. In the course of our research, we adopted the term 'stakeholder' - used within the industry - to signify all those who might, in some senses, be considered to be a customer of the new product development and design process, and the term 'end user' to signify someone at the end of this chain (or edge of this network) - a final consumer. In Nimrod's case the design engineers set up various tools and techniques to try and build up representations of otherwise inaccessible end users or customers: to access who the customers were, what their needs and wants might be, and 
what their use of the product or service was likely to be, and then tried to build them into the design and development process.

\section{What are the users' needs?}

Concern with meeting user needs more effectively has been one of the responses of telecom equipment suppliers to changes in their competitive environment following deregulation and privatisation, and the technological changes associated with the convergence of telecommunications and computer technologies. As in the computer industry, this concern with users has taken the form of improving the usability of the products marketed. But concern with usability does not necessarily equate with taking user needs into account, since usability evaluation exercises may not entail any involvement or participation of 'real' users during the design process, and does not take into account needs not addressed by the design on trial. Indeed, firms are really concerned more with identifying (potential) market demand than user needs as such.

It is the competitive pressures in the industry, which have encouraged firms to adopt strategies based on continuous innovation in the provision of new products, and on making sure that these products meet user needs, which have been translated for most practical purposes into the adoption of usability testing during the new production development process. In this way the firm retains a considerable degree of control over the definition of user needs even when it is apparently making a big effort to taken them into account. We focused on the usability process, despite these criticisms, because it is the approach on which the firms concerned have also focused.

Usability testing in general, and the usability testing carried out by Nimrod, took a very particular form in which to pay attention to users' needs: on the whole, the usability trials acted as a confirmation and justification of decisions more or less firmly made, rather than as a more open-ended exercise. Some design choices had been left open and were able to be made in the light of the trials. Some unexpected findings had to be taken into account. Sometimes the trials resulted in information that could not be incorporated in the design of the model under development, but would have to be adopted in future.

\section{Design in products and services}

In the research programme as a whole we had initially decided to explore the way in which users' needs were taken into account in the design of products. However, we concluded during the course of our research, and as a result of our meetings with firms, that there is a rather blurred boundary between what constitutes a product and what a service is, especially in high-tech industries such as telecommunications. Some activities (such as design), defined in official statistics as 'manufacturing' if carried out in a manufacturing firm, because 'services' if carried out by a subcontractor or design 
consultant. Gershuny and Miles (1985) have pointed out that various service needs have, over the years, increasingly been met by the purchase of goods rather than services (e.g. washing machines rather than laundries).

Providers of some services, especially in the finance sector, refer to their output as a 'product'. Manufacturers of products offer related services, especially where the product is a radical innovation, as an important strategy for market creation (as we have seen in the earlier discussion). Software is generally thought of as a product, but the physical product itself (floppy disc, CDROM) can equally be seen as the physical embodiment of the service provided by the programmer, which allows the user to perform certain tasks. Telecom service suppliers sell their 'own brand' telephones, fax machines, answering machines, and other equipment, which allow users to access their services. Indeed, they often offer packages which include services, infrastructure and equipment, ${ }^{8}$ and the consumer organisation we studied, when evaluating mobile phones, pays very little attention to the actual phone, and most to the financial 'deal' that comes with it and the geographical range of the network, on which the firms compete.

Telecom customers actually see and evaluate the product through which they access the service or final output of the whole infrastructure. Adding a further twist, as we have seen in the case of Nimrod and the P96, the design brief often requires the product itself to be 'transparent' and the system architecture 'invisible', meaning that the user should be aware only of the task undertaken (e.g. keeping in regular contact with staff overseas, the transfer of documents, data or molecular designs, or simultaneous work on a design by team members in different locations) and not the means by which it is done (the design of the equipment, or the service).

As a consequence of this blurring of boundaries, it was difficult to tell in advance whether the case study projects to which we were given access were going to concern the design of products or of services, or indeed a hybrid of the two. In this chapter we have focused on a product case study, but the project leader often referred to the product being designed as though it were a service: that is, it was seen as the means to an end, the end being the ability of the customer to access various telecommunications services and perform various tasks more easily than before.

\section{Conclusion}

The Nimrod case generated a great deal of information about usability procedures, what to take into account when designing them, how they fit in with the organisational structures and the order of work in a product development project, what questions to ask, how to make sense of what the users say, how to take account of observations of what they do, how to record such observations, the role of meetings, getting feedback from users and deciding how to take that feedback into account. It also provided a wealth of empirical material in which to base our understanding of the ways in which 
engineer-designers organise and understand their own work and take 'situated actions', 9 of the representation of users, negotiation in decision making and the achievement of closure, justification and transparency in decision making, the role of storytelling and scenarios in constructing shared understandings of the tasks at hand and in arguing a point of view, and the process of learning-by-doing and organisational learning.

Nimrod had firmly committed itself to a usability strategy, providing training for staff and a guide to usability testing, but our observations were of the first occasion on which the engineering team had tried to carry out a usability test on a real development project. Despite the training and the generic guidelines, many details of usability testing in their specific case had to be devised ad hoc by the project team, who had to deal with several unexpected issues.

The usability trials made the whole process more visible and accountable, allowing the consequences of design decisions to be traced, and providing information for the future about the kinds of decisions which should be left open at certain stages and the possible downstream consequences of taking others. The work of usability testing provided the means by which the engineers could learn not only about the product and its usability but also about the process of usability-oriented design. They learned by trial and error and through a process of learning by doing.

Focusing on the capture and incorporation of customers' or stakeholders' requirements means that organisations have to choose, select and introduce new design methods, tools and techniques, whose introduction involves a substantial shift in design practices and in the management of the design process. It is the actual application and practice of these new methods that is problematic for the organisation. We have identified some of the practical problems involved in utilising new design processes, and how they were solved (or caused the failure of a project). We hope by this means to contribute to the more efficient adoption by other firms of such new processes.

This emphasis differs from that in much of the management literature, which is often more concerned with devising or selecting new design processes to introduce, and/or with evaluating the efficacy of existing ones. Carrying out exercises to capture and integrate customer requirements involves a learning process that is essential to design effectiveness. We identified individuals' learning by doing and, even more important, organisational learning as an important part of innovative and design activity, particularly for firms in fast-moving technological areas.

Even firms which are committed to taking users into account, and which appear to have established a procedure for doing so, may discover that they have to go through a learning process in actually carrying out usability exercises. We found that new design methods to take customer requirements into account challenge designers' and managers' existing assumptions and practices, and involve negotiating between organisational, financial, technical and commercial constraints. We observed some of the knock-on effects 
caused by changes in the design process and its management as a result of introducing new design methods to take users into account.

In summary we would say that the project team did not acquire an objective, best practice, universally applicable and codifiable form of knowledge by a process of transfer from an expert or written account: instead they learned tacit skills and how to take 'situated' actions, drawing on local resources and their own subjective insights. They had to feel their way through the process, working out what to do as they went along.

\section{Acknowledgements}

We are grateful to all the staff at the company we have named Nimrod PLC who gave so generously of their time, and without whom this work would have been impossible. We would also like to thank the Design Council for the research funds that enabled us to carry out the study. Many colleagues have made useful comments on our work and shared ideas with us, particular thanks being due to Richard Hull.

\section{Notes}

1 However, it should be said that some design concerns cut across these different categories. The issue of designing for 'basic users' as against 'power users', that is, users who need step-by-step guidance compared with those with some experience who want to be able to take short cuts, is one of these.

2 In a development project the 'design authority' is a member of the team who is made responsible and accountable for such design matters as coherence and compatibility with previous company design, as well as with industry and worldwide technical standards etc. The design authority thus 'signs off' any design document.

3 In the phase review process established at Nimrod, and in most other firms in the industry, the objectives of each phase have to be shown to have been met, and a definite decision to proceed (or not) has to be taken, before moving on to the next phase.

4 The functional manager in charge of usability issues for that part of the company.

5 The working model (with the necessary electronic components and software) of the kind that is made immediately before going into production, and after all the design questions should have been answered and the usability issues addressed. This contrasts with the model described in the next note.

6 The non-working model (with neither electronic components nor software) can be connected to the computer so that users appear to be able to operate it, whereas it is actually the prototyping tool - that is, the computer software - that mimics the action of the telephone.

7 We visited a Nordic firm during the project, though not for an in-depth case study, and this firm did use members of the public for usability tests, but not when trying out a really radical innovation. Although the radical product might have needed a trial more than those with incremental changes, it was also thought to be most sensitive to intellectual property rights infringement on the part of competing firms. 
8 One of the designs submitted to the Design Business Association to be considered for an award for executive design was a telephone sold by a telecom service supplier. In the supporting case for the award it was argued that the design of the telephone was so pleasant to use and such an improvement over its competitors that users spent more time on the phone and made more phone calls. The service supplier would clearly have had an interest in selling such a phone, not simply to provide a range of products to allow customers to access their services (or to make a profit on the phone), but to encourage an increase in the use of the telecom service.

9 Actions which have to be adapted to the unforeseeable contingencies of particular situations, a term used by Lucy Suchman (1987) in her work in the Intelligent Systems Laboratory at Xerox Palo Alto Research Center. Purposeful action, however carefully planned in advance, has to be adapted to accommodate circumstances which are constantly changing and can never be fully anticipated.

\section{References}

Akrich, M. (1995), 'User representations: practices, methods and sociology', in Rip, A., Misa T., and Schot, J., Managing Technology in Society: the approach of constructive technology assessment, London, Pinter.

Cohen C., and Walsh, V. (1995), 'Networks and alliances in the design and innovation process', in Bennett, D., and Steward, F., Technological Innovation and Global Challenges, Birmingham, Aston Business School.

Coombs, R., Richards, A., Saviotti, P., and Walsh, V. (1996), Technological Collaboration: the dynamics of co-operation in innovation, Cheltenham, Elgar.

Dunning, J. (1997), Alliance Capitalism and Global Business, London, Routledge.

de Fornel, M. (1993), 'Faire parler les objets', in Pharo, P., and Quéré, L. (eds), Raisons pratiques I, Les Formes de l'action, Paris, EHESS.

Gershuny, J., and Miles, I. (1985), 'Towards a new social economics', in Roberts, B., Finnegan, R., and Gallie, D. (eds), New Approaches to Economic Life, Manchester, Manchester University Press.

Harper, R., and Hughes, J. (1993), “"What a f-ing system! Send 'em all to the same place and then expect us to stop 'em hitting": making technology work in air traffic control', Technical Report EPC-1991-125, Cambridge, Rank Xerox Research Centre.

Hull, R. (1997), 'Governing the conduct of the computer: computer science, the social sciences and frameworks of computing', Accounting, Management and Information Technology, 7, 213-40.

Hull, R. (1992), In Praise of Wimps: a social history of computer programming, Hebden Bridge: Alice Publications.

Hutchins, E. (1995), Cognition in the Wild, Cambridge MA, MIT Press.

Lundvall, B-Å. (1988), 'From user-supplier interaction to national systems of innovation', in Dosi, G., Freeman, C., Nelson, R., Soete, L., Silverberg, G., et al. (eds), Technological Change and Economic Theory, London, Pinter.

Mangematin, V. (1993), 'Recherche coopérative et stratégies de normalisation', doctoral thesis, Université de Paris IX Dauphine.

Mangematin, V., and Callon, M. (1995), 'Technological competition, strategies of forms, and choice of first users: the case of road guidance technologies', Research Policy, 24, 441-58. 
Miles, I. (1993), 'Bringing computer power to the consumer market', Technology Analysis and Strategic Management, 5 (2), pp. 151-72.

Nelson, R., and Winter, S. (1982), An Evolutionary Theory of Economic Change, Cambridge MA, Belknap Press of Harvard University Press.

Richards, A., Walsh, V., and Cohen, C. (1996), 'Usability and human-computer interaction', Background Paper I, CROMTEC (mimeo).

Suchman, L. (1987), Plans and Situated Actions, Cambridge, Cambridge University Press.

Suchman L. (1993), 'Technologies of accountability, of lizards and of aeroplanes', in Button, G. (ed.), Technology and Working Order, London, Routledge.

Von Hippel, E. (1988), The Sources of Innovation, New York, Oxford University Press.

Walsh, V. (1996), 'Design, innovation and the boundaries of the firm', Research Policy, 25, pp. 509-52. 